\title{
Augmented and Accelerated Nephrogenesis in TGF-ß32 Heterozygous Mutant Mice
}

\author{
SUNDER SIMS-LUCAS, GEORGINA CARUANA, JOHN DOWLING, MICHELLE M. KETT, AND JOHN F. BERTRAM \\ Department of Anatomy and Developmental Biology [S.S.-L., G.C., J.F.B.], Monash University, Melbourne 3800, Australia; \\ Department of Anatomical Pathology [J.D.], Alfred Hospital, Prahran 3181, Australia; Department of Physiology [M.M.K.], \\ Monash University, Melbourne 3800, Australia
}

\begin{abstract}
Several members of the transforming growth factor- $\beta$ (TGF- $\beta$ ) superfamily play key roles in kidney development, either directly or indirectly regulating nephron number. Although low nephron number is a risk factor for cardiovascular and renal disease, the implications of increased nephron number has not been examined due to the absence of appropriate animal models. Here, using unbiased stereology we demonstrated that kidneys from TGF- $\beta 2$ heterozygous (TGF- $\beta 2^{+/-}$) mice have approximately $60 \%$ more nephrons than wild-type mice at postnatal day 30. To determine whether augmented nephron number involved accelerated ureteric branching morphogenesis, embryonic day 11.5 metanephroi were analyzed via confocal microscopy. A $40 \%$ increase in total ureteric branch length was observed in TGF- $\beta 2^{+/-}$kidneys, together with an extra generation of branching. In embryonic day 12.5 metanephroi cultured for $48 \mathrm{~h}$ the numbers of both ureteric tree tips and glomeruli were significantly greater in TGF- $\beta 2^{+/-}$kidneys. These findings suggest that augmented nephron number in TGF- $\beta 2^{+/-}$kidneys results from accelerated ureteric branching morphogenesis and nephron formation. Manipulation of TGF- $\beta 2$ signaling in vivo may provide avenues for protection or rescue of nephron endowment in fetuses at risk. (Pediatr Res 63: 607-612, 2008)
\end{abstract}

$\mathrm{T}$ he development of the permanent mammalian kidney (metanephros) is a complex process requiring exquisite temporospatial regulation of multiple cellular events. Much has been learned in the past decade about these molecular regulatory processes (1-4), and the findings from recent microarray studies of gene expression during kidney development, including several studies from our own laboratory, provide much new information about the potential roles of specific genes and gene pathways (5-8).

Several members of the transforming growth factor- $\beta$ (TGF- $\beta$ ) superfamily of signaling molecules have been shown to play key roles in kidney development. These include TGF- $\beta 1$ (9), Activin A (10-12), bone morphogenetic protein 4 (13-15), bone morphogenetic protein 7 (16), and glial cell line-derived neurotrophic factor (GDNF) [reviewed in Shakya et al. $(17,18)$ and Cullen-McEwen et al. $(19,20)]$. However, little is known about the role of TGF- $\beta 2$ in kidney development. TGF- $\beta 2$ protein is expressed earlier in metanephric

Received October 9, 2007; accepted January 4, 2008.

Correspondence: John F. Bertram, Ph.D., Department of Anatomy and Developmental Biology, School of Biomedical Sciences, Monash University, Clayton, 3800, Australia; e-mail: john.bertram@med.monash.edu.au

This work was funded by a Monash University Small Grant and Faculty of Medicine Postgraduate Research Scholarship (to S.S.-L.), Monash University. development than TGF- $\beta 1$ and TGF- $\beta 3$ (21). TGF- $\beta 2$ gene expression has been detected in the kidney at embryonic day (E) 11.5 (22) and the protein localized in and around the ureteric epithelium and nephron structures from E12.5 $(21,23)$. TGF- $\beta 2$ homozygous null mutant mice (TGF- $\beta 2^{-1-}$ ) die within $24 \mathrm{~h}$ of birth due to defective lung development (24). The kidneys of these mice display progressive deterioration of the ureteric tubules and an enlarged renal pelvis after E15. No histologic renal phenotype has been reported in TGF- $\beta 2$ heterozygous null mutant mice (TGF- $\beta 2^{+/-}$). TGF- $\beta 2$ has been identified as a candidate molecule that is released from ureteric bud cells aiding in the survival and differentiation of metanephric mesenchyme (MM) (23). In combination with leukemia inhibitory factor, fibroblast growth factor-2 (FGF-2) and transforming growth factor- $\alpha$ (TGF $\alpha$ ), TGF- $\beta 2$ maintains isolated rat MM which can in turn be induced to differentiate (23).

Given the possible role of TGF- $\beta 2$ in mesenchymal cell survival and/or proliferation and knowing that growth factor concentrations can markedly influence developmental outcomes, we have examined in more detail the kidneys of postnatal TGF- $\beta 2^{+/-}$mice. First, we determined total nephron number, an index of overall kidney developmental outcome. To our surprise, the kidneys of TGF- $\beta 2^{+/-}$mice were found to contain $60 \%$ more nephrons than wild-type (WT) mice and these changes occurred without changes in urine production, osmolality, or albumin excretion. We then asked whether this augmented nephron endowment was the result of accelerated and/or extended nephrogenesis. Our results suggest that the augmented nephron endowment in TGF$\beta 2^{+/-}$mice is due to accelerated nephrogenesis.

\section{METHODS}

TGF- $\boldsymbol{\beta 2}$ mice. TGF- $\beta 2^{+/-}$mice (129/Black Swiss) were obtained from Dr. Thomas Doetschman (Department of Molecular Genetics, Biochemistry and Microbiology, University of Cincinnati, OH) and mated to obtain WT, TGF- $\beta 2^{+/-}$and TGF- $\beta 2^{-1-}$ mice. Genotyping was performed as previously described (24). All animal experiments were approved in advance by a Monash University animal ethics committee and were conducted in accor-

Abbreviations: E, embryonic; GDNF, glial-derived neurotrophic factor; MM, metanephric mesenchyme; $N_{\text {glom,kid }}$, total number of glomeruli per kidney; $\mathbf{P}$, postnatal; $\boldsymbol{V}_{\text {kid }}$, kidney volume; $\boldsymbol{V}_{\text {glom }}$, mean glomerular volume; $\boldsymbol{V}_{\text {corp }}$, mean renal corpuscle volume 
dance with the Australian Code of Practice for the Care and Use of Animals for Scientific Purposes.

Stereology. Total nephron number was determined in male and female WT and TGF- $\beta 2^{+1-}$ kidneys at P30. Mice were killed via cervical dislocation, body weights recorded and kidneys dissected, cleaned of fat and blood vessels, decapsulated and weighed. Kidneys were fixed in $10 \%$ buffered formalin. Left kidneys were embedded in glycolmethacrylate for nephron number estimation using an unbiased stereological method known as the physical disector/fractionator combination $(25,26)$.

Kidney volume and cortex-to-medulla ratio. Left kidneys were embedded whole in glycolmethacrylate and exhaustively sectioned at $20 \mu \mathrm{m}$. Every 10th and 11th sections were collected and stained with periodic acid schiff. Every 10th section was then placed onto a microfiche reader and viewed at a final magnification of $\times 24.25$. A $2 \mathrm{~cm}$ orthogonal grid was placed over the screen and points on the grid overlaying the kidney were counted as cortex $\left(P_{\mathrm{C}}\right)$, medulla $\left(P_{\mathrm{M}}\right)$ or renal pelvis $\left(P_{\mathrm{P}}\right)$. Kidney volume $\left(V_{\text {kid }}\right)$ was estimated using the Cavalieri Principle using the following equation:

$$
V_{\text {kid }}=P_{\mathrm{s}} \times a(p)_{\text {microfiche }} \times T \times 1 / f
$$

where $P_{\mathrm{s}}$ is the total number of points overlaying all kidney sections (sum of $\left.P_{\mathrm{C}}, P_{\mathrm{M}}, P_{\mathrm{P}}\right), a(p)_{\text {microfiche }}$ is the area associated with each grid point, $T$ is section thickness, and $1 / f$ is the inverse of the section sampling fraction. The cortex:medulla ratio $\left(V_{\mathrm{C}}: V_{\mathrm{M}}\right)$ was calculated using:

$$
V_{\mathrm{C}}: V_{\mathrm{M}}=P_{\mathrm{C}}: P_{\mathrm{M}}
$$

Nephron number. To estimate total nephron number in P30 kidneys, only complete pairs of sections were used. The section pairs were viewed side by side using two microscopes modified for projection. The microscope projecting the 10th section was fitted with a motorized stage (Autoscan Systems Pty, Ltd., Melbourne, Australia) that allowed fields to be sampled at predetermined intervals. The microscope projecting the 11th section was fitted with a manual rotatable stage to enable section alignment with the projection of the 10th section. A $2 \times 2 \mathrm{~cm}$ grid incorporating an unbiased counting frame (27) was placed over each field of view. Grid points that overlaid kidney tissue $\left(P_{\text {kid }}\right)$, glomeruli $\left(P_{\text {glom }}\right)$ and renal corpuscles $\left(P_{\text {corp }}\right)$ were tabulated. Glomeruli sampled by the unbiased counting frame of the 10th section that had disappeared from the 11th section were counted $\left(Q^{-}\right)$. Similarly, glomeruli present in the 11th section that were not present in the 10th section were also counted.

Total nephron number was estimated using:

$$
N_{\text {glom,kid }}=10 \times\left(P_{\mathrm{s}} / P_{\mathrm{f}}\right) \times\left[1 /\left(2 f_{\mathrm{a}}\right)\right] \times Q^{-}
$$

where $N_{\text {glom,kid }}$ is the total number of glomeruli (nephrons) per kidney, 10 is the inverse of the section sampling fraction, $P_{\mathrm{s}}$ is the total number of points overlaying all kidney sections (complete and incomplete), $P_{\mathrm{f}}$ is the total number of points overlaying complete kidney sections, $1 / 2 f_{\mathrm{a}}$ is the fraction of the total section area used to count glomeruli, where $f_{\mathrm{a}}$ is determined using:

$$
f_{\mathrm{a}}=\left[P_{\text {kid }} \times a(p) \text { of physical disector }\right] /\left[P_{\mathrm{f}} \times a(p) \text { of microfiche }\right]
$$

and $Q^{-}$was the actual number of glomeruli counted. The average number of glomeruli counted per kidney was 240 (range: 202-299) in WT mice and 370 in TGF- $\beta 2^{+/-}$mice (range: $321-412$ ).

Glomerular volume. Mean glomerular volume $\left(V_{\text {glom }}\right)$ was estimated using:

$$
V_{\text {glom }}=\left[V_{\text {glom }} / V_{\text {kid }}\right] /\left[N_{\text {glom }} / V_{\text {kid }}\right]
$$

where $V_{\text {glom }} / V_{\text {kid }}$ is equivalent to $P_{\text {glom }} / P_{\text {kid }}$.

The total volume of all glomeruli $V_{\text {glom,kid }}$ in a kidney was estimated using the following equation:

$$
V_{\text {glom,kid }}=V_{\text {glom }} \times N_{\text {glom,kid }}
$$

Renal corpuscle volume. Mean renal corpuscle volume $\left(V_{\text {corp }}\right)$ was estimated using:

$$
V_{\text {corp }}=\left[V_{\text {corp }} / V_{\text {kid }}\right] /\left[N_{\text {glom }} / V_{\text {kid }}\right]
$$

where $V_{\text {corp }} / V_{\text {kid }}$ is equivalent to $P_{\text {corp }} / P_{\text {kid }}$.

The total volume of all renal corpuscles $V_{\text {corp,kid }}$ was estimated using:

$$
V_{\text {corp,kid }}=V_{\text {corp }} \times N_{\text {glom,kid }}
$$

Histopathology. Right kidneys at P30 were embedded in paraffin and $5 \mu \mathrm{m}$ sections stained with hematoxylin and eosin, periodic acid schiff, Masson's trichrome, and silver methenamine and examined in a blinded manner for signs of histopathology by an expert renal pathologist (J.D.).
Basic renal function. Eight $\mathrm{WT}$ and eight TGF- $\beta 2^{+/-}$P70 male mice were placed into metabolic cages and $24 \mathrm{~h}$ urine production was measured and urinary osmolality determined by freezing point depression (Advanced Osmometer 2020, Advanced Instruments, Needham Heights, MA) and urinary albumin was determined using a murine specific ELISA (Exocell Inc, Philadelphia, PA).

Histology. To determine when nephrogenesis finished in WT and TGF$\beta 2^{+/-}$mice, the kidneys of 10 mice of each genotype were examined at each postnatal day from P1 to P9. Pups were decapitated and kidneys immersionfixed in $10 \%$ neutral buffered formalin before processing for embedding in paraffin. Five micrometers sections were stained with hematoxylin and eosin. Nephrogenesis was deemed to be completed when there was no longer the presence of comma or S-shaped bodies.

Organ culture. For whole metanephric organ culture studies, TGF- $\beta 2^{+/-}$ mice were time-mated, with E0.5 defined as midday on the day on which a vaginal plug was found. Metanephroi dissected from E12.5 WT, TGF- $\beta 2^{+/-}$, and TGF- $\beta 2^{-1-}$ staged embryos and cultured on transfilter polycarbonate membranes (Costar, $\mathrm{NY}$ ) at $37^{\circ} \mathrm{C}$ with $5 \% \mathrm{CO}_{2}$ in Dulbecco's Modified Eagle's Medium, Ham's F12 liquid medium (Trace Biosciences, Castle Hill, NSW, Australia) including supplements: $5 \mu \mathrm{g} / \mathrm{mL}$ transferrin (Sigma Chemical Co.-Aldrich, Castle Hill, NSW, Australia), $2.5 \mathrm{mM}$ L-glutamine (Trace Bioscience), $100 \mu \mathrm{g} / \mathrm{mL}$ penicillin (Trace Bioscience) and $100 \mu \mathrm{g} / \mathrm{mL}$ streptomycin (Trace Bioscience). Following $48 \mathrm{~h}$ culture, whole metanephroi were fixed in ice-cold methanol until further use.

Calbindin- $D_{28 k}$ and WT-1 wholemount immunofluorescence. Immunohistochemistry for Calbindin- $\mathrm{D}_{28 \mathrm{k}}$ and Wilms' tumor 1 (WT1) was performed on cultured metanephroi to visualize and quantify branching morphogenesis and glomerular number, respectively. Following fixation, metanephroi were washed in PBS and then nonspecific blocking with 5\% FCS was conducted in PBS at room temperature. This was then followed with the primary antibodies: monoclonal mouse anti-Calbindin- $\mathrm{D}_{28 \mathrm{k}}$ (Sigma Chemical Co.-Aldrich) and rabbit anti-mouse anti-WT1 (Santa Cruz, CA) at a dilution of 1:100, at $37^{\circ} \mathrm{C}$ for $1 \mathrm{~h}$. Metanephroi were washed in PBS before the addition of the secondary antibodies: Alexa 488 goat anti-mouse (Molecular Probes) and Alexa 594 goat anti-rabbit (Molecular Probes) at a dilution of $1: 500$, at $37^{\circ} \mathrm{C}$ for $1 \mathrm{~h}$. Metanephroi were then washed in PBS for several hours before mounting in PBS/glycerol mounting media (Sigma Chemical Co.-Aldrich).

Confocal microscopy and image analysis. E11.5 time-mated pregnant females were killed and the kidneys of $10 \mathrm{WT}$ and $10 \mathrm{TGF}-\beta 2^{+/-}$staged embryos removed and placed into ice-cold methanol. Kidneys were stained with Calbindin- $\mathrm{D}_{28 \mathrm{k}}$ as described above before being optically sectioned with a $10 \times$ lens on a Leica TCS NT confocal microscope, until a Z stack of all images was obtained [as previously described (13)]. Image processing and analysis software (28) were then used to obtain estimates of the length of the ureteric tree in three dimensions.

Statistical analysis. All results are given as means \pm SD. Stereological data were analyzed using either a one-way or two-way analysis of variance (ANOVA) as appropriate. Basic renal physiologic measures were analyzed using a student $t$ test. In vitro data were analyzed using a one-way ANOVA, followed by a Tukey post hoc test as required. A probability of 0.05 or less was considered statistically significant.

\section{RESULTS}

Nephron number is augmented in TGF- $\beta 2^{+/-}$mice. The kidneys of female TGF- $\beta 2^{+/-}$mice at P30 contained $20,501 \pm 1793$ glomeruli (nephrons) compared with 12,748 \pm 1438 in WT littermates $(p<0.0001$; Table 1$)$. This equates to a remarkable $61 \%$ increase in total glomerular number in the female TGF- $\beta 2^{+/-}$mice. A similar increase in total nephron number was observed in male TGF- $\beta 2^{+/-}$kidneys compared with WT kidneys, with the difference being $63 \%$. Body weights of both female and male TGF- $\beta 2^{+/-}$mice at P30 were not statistically different to WT mice. Kidney weight tended to be higher in both male and female TGF- $\beta 2^{+/-}$mice than in WT mice $(p=0.127)$ although these differences were not statistically significant. However, kidney volume was $27 \%$ greater in female TGF- $\beta 2^{+/-}$mice $(p<0.05)$ than WT mice, and $22 \%$ larger in male TGF- $\beta 2^{+/-}$mice $(p<0.05)$. Mean 
Table 1. Body weights, kidney weights, kidney volumes, and stereological data for male and female WT and TGF- $\beta 2^{+/-}$mice at P30

\begin{tabular}{|c|c|c|c|c|}
\hline & $\begin{array}{c}\text { WT } \\
\text { females } \\
(\mathrm{n}=7)\end{array}$ & $\begin{array}{c}\text { TGF- } \beta 2^{+/-} \\
\text {females } \\
(\mathrm{n}=7)\end{array}$ & $\begin{array}{c}\text { WT } \\
\text { males } \\
(\mathrm{n}=7)\end{array}$ & $\begin{array}{c}\text { TGF- } \beta 2^{+/-} \\
\text {males } \\
(\mathrm{n}=7)\end{array}$ \\
\hline Body weight $(\mathrm{g})$ & $17.6 \pm 2.8$ & $18.7 \pm 1.9$ & $20.3 \pm 3.0$ & $21.0 \pm 1.5$ \\
\hline Kidney weight (mg) & $104 \pm 19$ & $115 \pm 17$ & $125 \pm 22$ & $143 \pm 13$ \\
\hline Kidney volume $\left(V_{\text {kid }} ; \mathrm{mm}^{3}\right)$ & $115 \pm 27$ & $145 \pm 15^{*}$ & $144 \pm 22$ & $175 \pm 21 *$ \\
\hline Cortex-to-medulla ratio & $1.72 \pm 0.08$ & $1.68 \pm 0.06$ & $1.63 \pm 0.07$ & $1.75 \pm 0.07$ \\
\hline Total glomerular number & $12,748 \pm 1438$ & $20,501 \pm 1793 \dagger$ & $12,283 \pm 663$ & $19,978 \pm 1148 \dagger$ \\
\hline Glomerular volume $\left(V_{\text {glom }} ; \times 10^{-4} \mathrm{~mm}^{3}\right)$ & $1.80 \pm 0.42$ & $1.47 \pm 0.27$ & $1.81 \pm 0.33$ & $1.39 \pm 0.14 \ddagger$ \\
\hline Total glomerular volume $\left(V_{\text {glom,kid }} ; \mathrm{mm}^{3}\right)$ & $2.29 \pm 0.60$ & $3.00 \pm 0.53 *$ & $2.22 \pm 0.40$ & $2.78 \pm 0.27 *$ \\
\hline Renal corpuscle volume $\left(V_{\text {corp }} ; \times 10^{-4} \mathrm{~mm}^{3}\right)$ & $2.44 \pm 0.51$ & $1.90 \pm 0.24 *$ & $2.44 \pm 0.50$ & $1.85 \pm 0.24 *$ \\
\hline Total renal corpuscle volume $\left(V_{\text {corp,kid }} ; \mathrm{mm}^{3}\right)$ & $3.10 \pm 0.69$ & $3.87 \pm 0.48^{*}$ & $2.99 \pm 0.58$ & $3.69 \pm 0.41^{*}$ \\
\hline
\end{tabular}

Values are means $\pm \mathrm{SD}$.

$* p<0.05$.

$\dagger p<0.0001$.

$\ddagger p<0.01$.

glomerular volume was $19 \%$ smaller in female TGF- $\beta 2^{+/-}$ mice $(p<0.05)$ and $23 \%$ smaller in male TGF- $\beta 2^{+/-}$mice $(p<0.05)$ compared with WT littermates. The total volume of all glomeruli in the kidney was $25 \%$ higher in female $(p<$ $0.05)$ and $23 \%$ higher in male TGF- $\beta 2^{+/-}$mice $(p<0.05)$ than in WT mice (Table 1). No difference was observed in the cortex-to-medulla ratio in TGF- $\beta 2^{+/-}$mice. No evidence of renal histopathology was observed in either WT or TGF- $\beta 2^{+/-}$ mice at P30 (data not shown).

Urine osmolality. No statistical difference was observed in mean urine production (WT, $1.92 \pm 0.14 \mathrm{~mL} / 24 \mathrm{~h}$; TGF- $\beta 2^{+/-}$, $2.01 \pm 0.16 \mathrm{~mL} / 24 \mathrm{~h}$ ), urine osmolality (WT, $2018 \pm 336$ $\mathrm{mosmol} / \mathrm{kg} \mathrm{H}_{2} \mathrm{O}$; TGF- $\beta 2^{+/-}, 1713 \pm 748 \mathrm{mosmol} / \mathrm{kg} \mathrm{H}_{2} \mathrm{O}$ ), or albumin excretion (WT, $76.01 \pm 5.05 \mu \mathrm{g} / 24 \mathrm{~h}$; TGF- $\beta 2^{+/-}$, $67.13 \pm 5.98 \mu \mathrm{g} / 24 \mathrm{~h}$ ) between WT and TGF- $\beta 2^{+/-}$male mice at $\mathrm{P} 70$.

Nephrogenesis ends between P4 and P5 in WT and TGF$\boldsymbol{\beta} 2^{+/-}$kidneys. To determine whether the augmented nephron number in TGF- $\beta 2^{+/-}$mice was due in part to an extended period of nephrogenesis, kidneys of WT and TGF- $\beta 2^{+/-}$mice were histologically examined from P1 to P9. Nephrogenesis (as defined by the presence of comma and S-shaped bodies) finished between P4 and P5 in both WT and TGF- $\beta 2^{+/-}$ kidneys. At P4, a clearly defined nephrogenic zone was present in both WT and TGF- $\beta 2^{+/-}$kidneys (Fig. 1), with S-shaped bodies evident (Fig. 1). However, by P5 the nephrogenic zone and $\mathrm{S}$-shaped bodies were no longer evident (Fig. 1), indicating the cessation of nephrogenesis.

Accelerated branching morphogenesis and nephrogenesis in $\mathbf{T G F}-\boldsymbol{\beta 2}^{+/-}$mice. To determine whether the augmented nephron number in P30 TGF- $\beta 2^{+/-}$mice was due to accelerated branching morphogenesis resulting in accelerated nephrogenesis, two approaches were undertaken. Firstly, ureteric trees were assessed in WT and TGF- $\beta 2^{+/-}$metanephroi at E11.5. TGF- $\beta 2^{+/-}$metanephroi were found to have undergone an extra branching event compared with WT littermates (Fig. $2 A$ and $B$ ). This was reflected by a $40 \%$ increase in total ureteric tree length (Fig. $2 C$ ) in the TGF- $\beta 2^{+/-}$metanephroi. The lengths of both the anterior and posterior regions of the ureteric tree were greater in the TGF- $\beta 2^{+/-}$kidneys (Fig. $2 D$ ). To further investigate ureteric tree growth, whole metanephroi from E12.5 WT, TGF- $\beta 2^{+/-}$, and TGF- $\beta 2^{-/-}$mice were
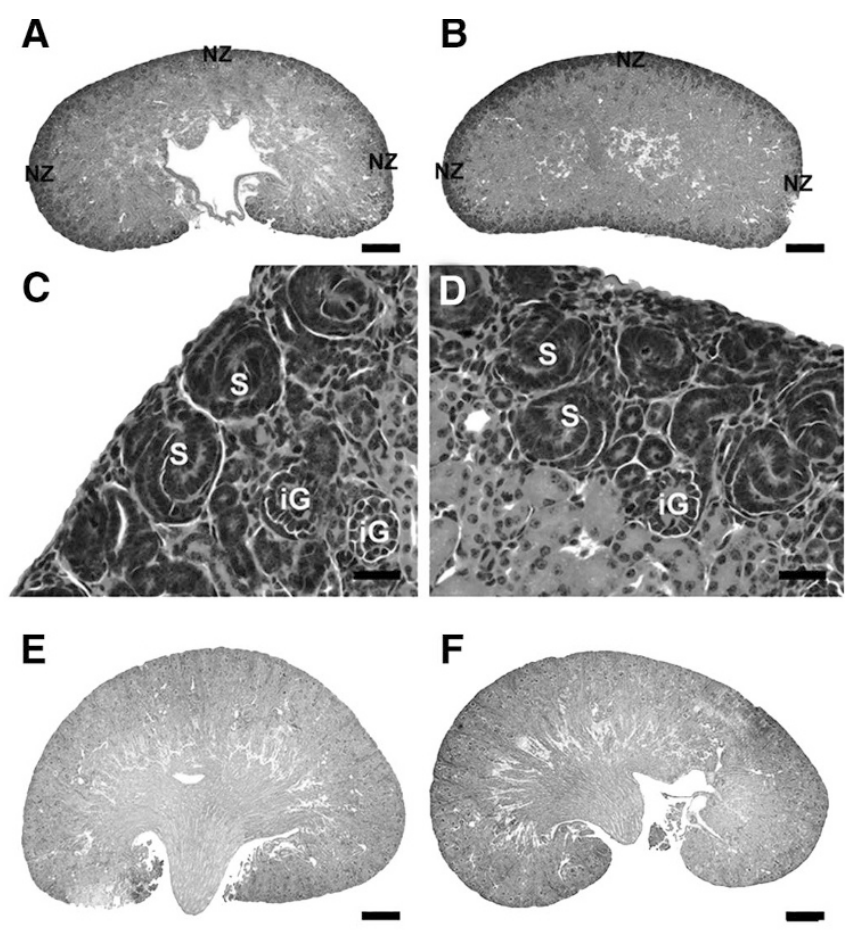

G

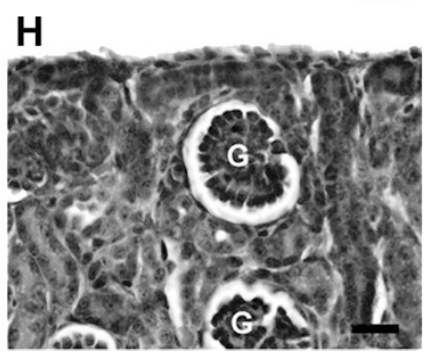

Figure 1. Completion of nephrogenesis in WT and TGF- $\beta 2^{+/-}$kidneys. P4 WT $(A)$ and TGF- $\beta 2^{+/-}(B)$ kidney with clearly defined nephrogenic zone (NZ). P4 WT $(C)$ and TGF- $\beta 2^{+/-}(D)$ kidney showing S-shaped bodies (S) and immature glomeruli (iG) in the nephrogenic zone. The nephrogenic zone is no longer evident at P5 in either WT $(E, G)$ or TGF- $\beta 2^{+/-}(F, H)$ kidneys. Periphery of a P5 WT $(G)$ and TGF- $\beta 2^{+/-}(H)$ kidney demonstrating absence of a nephrogenic zone. Glomerulus $(\mathrm{G})$. Scale bar $A, B, E, F=100 \mu \mathrm{m}$, Scale bar $C, D, G, H=25 \mu \mathrm{m}$.

cultured for $48 \mathrm{~h}$. Ureteric branching in metanephric explants from TGF- $\beta 2^{+/-}$mice appeared grossly normal though the degree of branching was greater than that of the WT (Fig. 3E). 

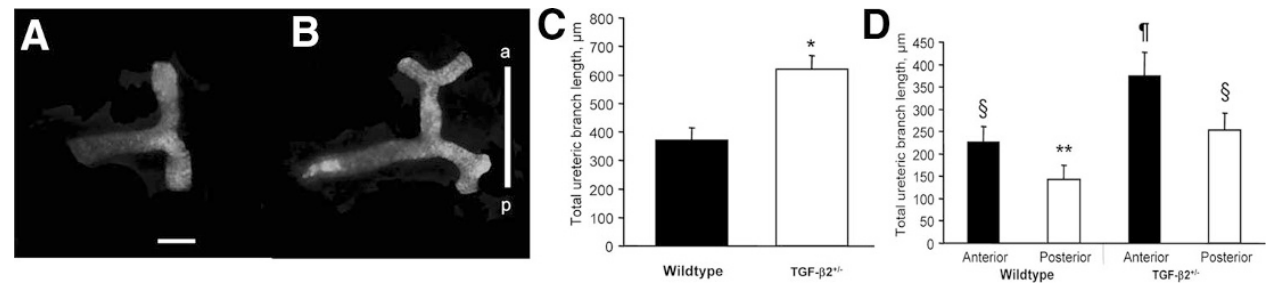

Figure 2. Effect of decreased endogenous levels of TGF- $\beta 2$ on branching morphogenesis. Reconstructed three-dimensional image of ureteric tree in E11.5 WT $(A)$ and TGF- $\beta 2^{+/-}(B)$ kidney with the anterior (a) and posterior (p) axis demonstrated. Scale bar $=100 \mu \mathrm{m}$. $(C)$ Histogram of total ureteric branch length in WT and TGF- $\beta 2^{+/-}$kidneys. $(D)$ Histogram of total ureteric branch length in anterior and posterior compartments of WT and TGF- $\beta 2^{+/-}$kidneys. Values are means $\pm \mathrm{SD}, * p<0.0001$ in comparison with WT value. Columns in $D$ depicted by $* *$ and $\mathbb{\text { If }}$ are significantly different $(p<0.001)$, whereas columns depicted with $\S$ are not significantly different. ( $n=10$ per genotype).
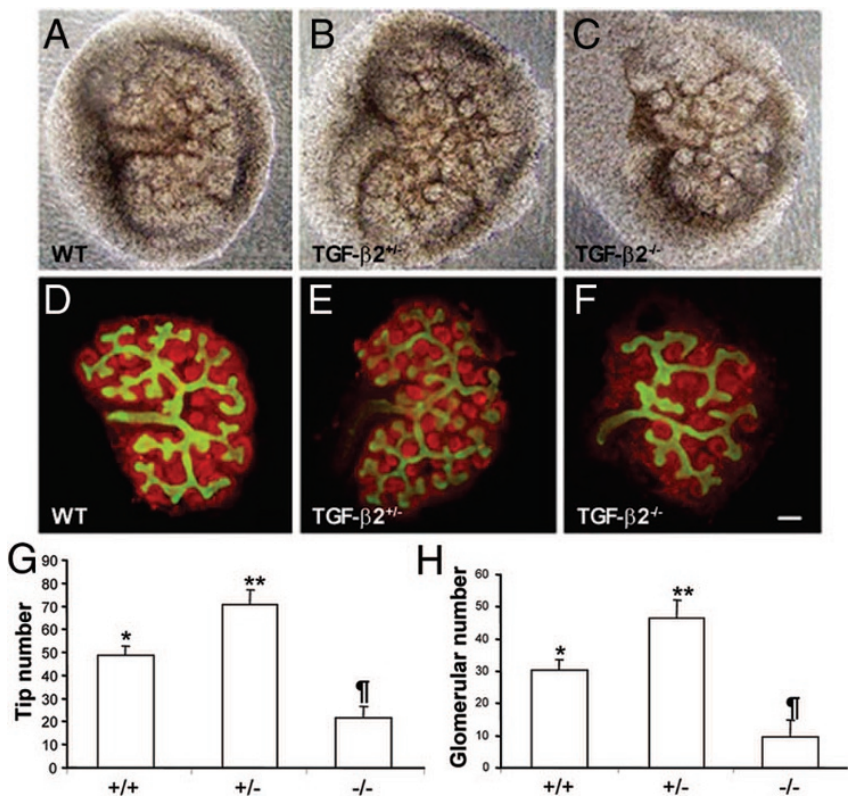

Figure 3. Effect of decreased endogenous levels of TGF- $\beta 2$ on branching morphogenesis and nephron endowment. $(A-C)$ Phase contrast images of WT, TGF- $\beta 2^{+/-}$and TGF- $\beta 2^{-/-}$kidneys cultured for $48 \mathrm{~h}$. $(D-F)$ Immunohistochemistry of WT, TGF- $\beta 2^{+/-}$, and TGF- $\beta 2^{-1-}$ kidneys co-immunostained for Calbindin- $\mathrm{D}_{28 \mathrm{k}}$ (ureteric epithelium) and WT1 (glomerular podocytes). TGF- $\beta 2^{+/-}$kidneys $(B, E)$ appear to have a similar branching pattern to WT $(A, D)$ kidneys, though the number of branches is increased. Conversely, the branching pattern is grossly abnormal in TGF- $\beta 2^{-1-}$ kidneys $(C, F)$ and less nephrons are apparent. Scale bar $=50 \mu \mathrm{m}$. Histograms of branch tip number $(G)$ and total glomerular number $(H)$ in WT, TGF- $\beta 2^{+/-}$and TGF- $\beta 2^{-1-}$ kidneys cultured for $48 \mathrm{~h}$. TGF- $\beta 2^{+/-}$metanephroi contained significantly more branch tips and glomeruli than WT metanephroi $(p<0.0001$ in each case). TGF- $\beta 2^{-/-}$kidneys contained significantly fewer branch tips and glomeruli than WT kidneys. Values are means $\pm \mathrm{SD}$. *, ** and II depict significant differences $(p<0.0001)$ in comparison with WT value. $(n=10$ per genotype).

However, ureteric branching in TGF- $\beta 2^{-/-}$metanephroi was reduced in comparison with both WT and TGF- $\beta 2^{+/-}$metanephroi and the pattern of ureteric branching appeared abnormal (Fig. 3F). Quantitative analysis of branching morphogenesis in cultured metanephroi revealed a $45 \%$ increase in ureteric tip number $(p<0.001)$ in TGF- $\beta 2^{+/-}$explants compared with WT explants (Fig. $3 G$ ). This was associated with a $54 \%$ increase in glomerular number $(p<0.001$; Fig. $3 H)$. In contrast, TGF- $\beta 2^{-/-}$explants contained $56 \%$ fewer branch tips $(p<0.001$; Fig. $3 G)$ and $69 \%$ fewer glomeruli $(p<0.001)$ than WT kidneys (Fig. $3 H)$.

\section{DISCUSSION}

The major findings from the present study are: 1) the kidneys of TGF- $\beta 2^{+/-}$mice contain approximately $60 \%$ more nephrons than the kidneys of WT mice; 2) this augmented nephron endowment is not due to extension of the normal period of nephrogenesis but rather to accelerated branching morphogenesis and associated nephrogenesis; 3 ) renal histology is normal at P30 in TGF- $\beta 2^{+/-}$mice despite the accelerated and augmented nephrogenesis; and 4) ureteric branching morphogenesis is retarded and abnormal in TGF- $\beta 2^{-/-}$ mice.

TGF- $\mathrm{B2}^{+/-}$mice have a $60 \%$ increase in nephron number. No qualitative phenotypic differences were observed between the kidneys of TGF- $\beta 2^{+/-}$and WT mice; however, glomerular number was significantly increased in TGF- $\beta 2^{+/-}$ mice. This finding to our knowledge is the first report linking decreased expression of a growth factor with increased nephron endowment. Previously, decreased endogenous activity of genes has been linked with a nephron deficit. Decreased nephron number associated with deletion of one allele has been reported in relation to GDNF (19,20), FGF-7 (29), FGFR1/2 (30), and Pax2 (31) among others. Maeshima et al. (10) were the first to report an increase in nephron endowment in relation to decreased signaling, when they found that truncation of the type II Activin receptor (which acts as a dominant negative receptor blocking Activin A signaling) resulted in a dramatic increase in nephron endowment. Activin A is normally an inhibitor of branching morphogenesis (12). Maeshima et al. (10) hypothesized that alleviating this inhibition would result in increased branching, leading to increased nephron number.

With the large increase in nephron endowment and total glomerular volume in TGF- $\beta 2^{+/-}$mice, it was interesting that there was no alteration in cortex-to-medulla ratio. It is also likely that there is a decrease in the length of the cortical tubules although this was not measured in the current study. When we examined both urine output and osmolality, there were no differences between WT and TGF- $\beta 2^{+/-}$mice. The findings here may be partially offset by the decrease in glomerular size. It was also interesting to note that the glomerular filtration barrier seems to be normal under control conditions in TGF- $\beta 2^{+/-}$mice as expressed by normal albumin excretion levels. These observations are consistent with earlier findings under control conditions in TGF- $\beta 2^{+/-}$mice (32). When kidneys were examined at P30, it was clear that there were no 
signs of renal pathology. We are currently studying older TGF- $\beta 2^{+/-}$mice to determine whether they have a predisposition to renal disease.

Increased nephron endowment is due to accelerated ureteric branching morphogenesis and nephrogenesis in $\boldsymbol{T G F}-\boldsymbol{\beta 2}^{+/-}$kidneys. Nephrogenesis in rats (33) and mice (34) continues for the first few days postnatally. Nephrogenesis was found to cease at the same time point (between $\mathrm{P} 4$ and P5) in both WT and TGF- $\beta 2^{+/-}$kidneys. We therefore analyzed ureteric branching morphogenesis in the TGF- $\beta 2^{+/-}$ kidneys as a possible determinant of the augmented nephron number. Previously, exogenous GDNF (18), retinoic acid $(35,36)$, and Follistatin (12) have been reported to increase nephron number in metanephric organ culture. However, it has not previously been reported that a similar outcome can occur when expression of a ligand is down-regulated. Interestingly, in the case of the TGF- $\beta 2^{+/-}$kidneys, increased branching morphogenesis was seen as early as E11.5. Previous reports have demonstrated that addition of TGF- $\beta 2$ to metanephric organ culture decreases branching morphogenesis. This was attributed to a decrease in cell proliferation $(37,2,12)$. It is possible that in the present study, the accelerated ureteric branching morphogenesis is the result of accelerated cell proliferation.

Decreased branching morphogenesis and nephron en-

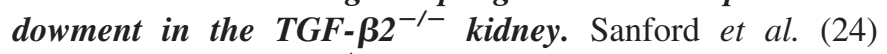
reported that TGF- $\beta 2^{-1-}$ mice displayed varying renal phenotypes, ranging from complete renal agenesis to a dilated renal pelvis, with the underlying characteristic being a progressive deterioration of epithelial tubules after E15.5. The present study demonstrates that from E12.5 the absence of TGF- $\beta 2$ was associated with dramatic decreases in both branch tip and glomerular number in vitro. TGF- $\beta 2$ is known to negatively regulate branching morphogenesis $(37,2,12)$. However, the complete absence of TGF- $\beta 2$ (in homozygous mutants) also has an inhibitory effect on branching morphogenesis and nephron endowment. Ureteric branching morphogenesis is a complex process that involves an extensive hierarchy of molecules. These molecules must cooperate (both spatially and temporally) with molecules released from the MM to produce normal branching morphogenesis. In the absence of TGF- $\beta 2$ (in homozygous mutants), signaling between the ureteric epithelium and $\mathrm{MM}$ is interrupted, inhibiting the development of both these structures, as seen by the decrease in branching morphogenesis and nephron endowment.

Gene dosage in TGF- 32 mutant mice regulates branching morphogenesis and nephron endowment. Based on the findings reported in the present study we propose the following model. TGF- $\beta 2$ has been shown to be a negative regulator of branching morphogenesis in the kidney $(37,2,12)$. When TGF- $\beta 2$ is present but levels are reduced, as in TGF- $\beta 2^{+/-}$ mice, this negative regulation is decreased, resulting in enhanced branching and an associated increase in nephron number. It might be assumed that by completely blocking TGF- $\beta 2$ activity (as in the TGF- $\beta 2^{-/-}$kidney), ureteric branching morphogenesis will be even further accelerated and nephron endowment further increased. However, complete loss of TGF- $\beta 2$ results in a similar phenotype to that observed fol- lowing culture with high levels of exogenous TGF- $\beta 2$ $(37,2,12)$. This may be due to the fact that TGF- $\beta 2$ is also a survival factor for the mesenchyme (23). The loss of functional mesenchyme as an active inducer of branching may explain the severe inhibition of both branching and nephrogenesis in the TGF- $\beta 2^{-/-}$mice. However, in the TGF- $\beta 2^{+/-}$ metanephroi there must be sufficient levels of TGF- $\beta 2$ to allow survival of the mesenchyme for nephrogenesis still to occur. These findings suggest there is a critical and possible narrow range of TGF- $\beta 2$ concentrations required for normal branching and nephrogenesis.

In conclusion, TGF- $\beta 2$ regulates ureteric branching morphogenesis and nephron endowment in a dose-dependant manner. Further characterization of the effects of varying the levels of TGF- $\beta 2$ in the developing kidney will aid in the understanding of this complex developmental process. If the process of regulating TGF- $\beta 2$ levels to increase nephron number can be safely harnessed and proven to be physiologically significant, this may have therapeutic benefits.

Acknowledgments. We thank Andrew Jefferies, Sue Connell, and Julie Hickey for their assistance.

\section{REFERENCES}

1. Bouchard M, Souabni A, Mandler M, Neubuser A, Busslinger M 2002 Nephric lineage specification by Pax2 and Pax8. Genes Dev 16:2958-2970

2. Costantini F, Shakya R 2006 GDNF/Ret signaling and the development of the kidney. Bioessays 28:117-127

3. Cullen-McEwen LA, Caruana G, Bertram JF 2005 The where, what and why of the developing renal stroma. Nephron Exp Nephrol 99:e1-e8

4. Yosypiv IV, El-Dahr SS 2005 Role of the renin-angiotensin system in the development of the ureteric bud and renal collecting system. Pediatr Nephrol 20:1219-1229

5. Caruana G, Cullen-McEwen L, Nelson AL, Kostoulias X, Woods K, Gardiner B, Davis MJ, Taylor DF, Teasdale RD, Grimmond SM, Little MH, Bertram JF 2006 Spatial gene expression in the T-stage mouse metanephros. Gene Expr Patterns 6:807-825

6. Challen G, Gardiner B, Caruana G, Kostoulias X, Martinez G, Crowe M, Taylor DF, Bertram J, Little M, Grimmond SM 2005 Temporal and spatial transcriptional programs in murine kidney development. Physiol Genomics 23:159-171

7. Mitchell EK, Taylor DF, Woods K, Davis MJ, Nelson AL, Teasdale RD, Grimmond SM, Little MH, Bertram JF, Caruana G 2006 Differential gene expression in the developing mouse ureter. Gene Expr Patterns 6:519-538

8. Patterson LT, Potter SS 2004 Profiling gene expression in kidney development. Nephron Exp Nephrol 98:e109-e113

9. Clark AT, Young RJ, Bertram JF 2001 In vitro studies on the roles of transforming growth factor-beta 1 in rat metanephric development. Kidney Int 59:1641-1653

10. Maeshima A, Shiozaki S, Tajima T, Nakazato Y, Naruse T, Kojima I 2000 Number of glomeruli is increased in the kidney of transgenic mice expressing the truncated type II activin receptor. Biochem Biophys Res Commun 268:445-449

11. Maeshima A, Yamashita S, Maeshima K, Kojima I, Nojima Y 2003 Activin a produced by ureteric bud is a differentiation factor for metanephric mesenchyme. J Am Soc Nephrol 14:1523-1534

12. Ritvos O, Tuuri T, Eramaa M, Sainio K, Hilden K, Saxen L, Gilbert SF 1995 Activin disrupts epithelial branching morphogenesis in developing glandular organs of the mouse. Mech Dev 50:229-245

13. Cain JE, Nion T, Jeulin D, Bertram JF 2005 Exogenous BMP-4 amplifies asymmetric ureteric branching in the developing mouse kidney in vitro. Kidney Int 67:420-431

14. Miyazaki Y, Oshima K, Fogo A, Hogan BL, Ichikawa I 2000 Bone morphogenetic protein 4 regulates the budding site and elongation of the mouse ureter. J Clin Invest 105:863-873

15. Raatikainen-Ahokas A, Hytonen M, Tenhunen A, Sainio K, Sariola H 2000 BMP-4 affects the differentiation of metanephric mesenchyme and reveals an early anteriorposterior axis of the embryonic kidney. Dev Dyn 217:146-158

16. Piscione TD, Yager TD, Gupta IR, Grinfeld B, Pei Y, Attisano L, Wrana JL, Rosenblum ND 1997 BMP-2 and OP-1 exert direct and opposite effects on renal branching morphogenesis. Am J Physiol 273:F961-F975

17. Shakya R, Jho EH, Kotka P, Wu Z, Kholodilov N, Burke R, D'Agati V, Costantini F 2005 The role of GDNF in patterning the excretory system. Dev Biol 283:70-84

18. Shakya R, Watanabe T, Costantini F 2005 The role of GDNF/Ret signaling in ureteric bud cell fate and branching morphogenesis. Dev Cell 8:65-74

19. Cullen-McEwen LA, Drago J, Bertram JF 2001 Nephron endowment in glial cell line-derived neurotrophic factor (GDNF) heterozygous mice. Kidney Int 60:31-36 
20. Cullen-McEwen LA, Kett MM, Dowling J, Anderson WP, Bertram JF 2003 Nephron number, renal function, and arterial pressure in aged GDNF heterozygous mice. Hypertension 41:335-340

21. Pelton RW, Saxena B, Jones M, Moses HL, Gold LI 1991 Immunohistochemical localization of TGF beta 1 , TGF beta 2 , and TGF beta 3 in the mouse embryo: expression patterns suggest multiple roles during embryonic development. J Cell Biol 115:1091-1105

22. Oxburgh L, Chu GC, Michael SK, Robertson EJ 2004 TGFbeta superfamily signals are required for morphogenesis of the kidney mesenchyme progenitor population. Development 131:4593-4605

23. Plisov SY, Yoshino K, Dove LF, Higinbotham KG, Rubin JS, Perantoni AO 200 TGF beta 2, LIF and FGF2 cooperate to induce nephrogenesis. Development 128:1045-1057

24. Sanford LP, Ormsby I, Gittenberger-de Groot AC, Sariola H, Friedman R, Boivin GP, Cardell EL, Doetschman T 1997 TGFbeta2 knockout mice have multiple developmental defects that are non-overlapping with other TGFbeta knockout phenotypes. Development 124:2659-2670

25. Bertram JF 1995 Analyzing renal glomeruli with the new stereology. Int Rev Cytol 161:111-172

26. Bertram JF, Soosaipillai MC, Ricardo SD, Ryan GB 1992 Total numbers of glomeruli and individual glomerular cell types in the normal rat kidney. Cell Tissue Res 270:37-45

27. Gundersen HJ 1977 Notes on the estimation of the numerical density of arbitary profiles: the edge effect. J Microsc 111:219-223

28. Cullen-McEwen LA, Fricout G, Harper IS, Jeulin D, Bertram JF 2002 Quantitation of $3 \mathrm{D}$ ureteric branching morphogenesis in cultured embryonic mouse kidney. Int $\mathrm{J}$ Dev Biol 46:1049-1055
29. Qiao J, Uzzo R, Obara-Ishihara T, Degenstein L, Fuchs E, Herzlinger D 1999 FGF-7 modulates ureteric bud growth and nephron number in the developing kidney. Development 126:547-554

30. Poladia DP, Kish K, Kutay B, Bauer J, Baum M, Bates CM 2006 Link between reduced nephron number and hypertension: studies in a mutant mouse model. Pediatr Res 59:489-493

31. Dziarmaga A, Eccles M, Goodyer P 2006 Suppression of ureteric bud apoptosis rescues nephron endowment and adult renal function in Pax2 mutant mice. J Am Soc Nephrol 17:1568-1575

32. Pietri L, Bloch-Faure M, Belair MF, Sanford LP, Doetschman T, Menard J, Bruneval P, Meneton P 2002 Altered renin synthesis and secretion in the kidneys of heterozygous mice with a null mutation in the TGF-beta(2) gene. Exp Nephrol 10:374-382

33. Lelievre-Pegorier M, Vilar J, Ferrier ML, Moreau E, Freund N, Gilbert T, MerletBenichou C 1998 Mild vitamin A deficiency leads to inborn nephron deficit in the rat. Kidney Int 54:1455-1462

34. Cebrian C, Borodo K, Charles N, Herzlinger DA 2004 Morphometric index of the developing murine kidney. Dev Dyn 231:601-608

35. Moreau E, Vilar J, Lelievre-Pegorier M, Merlet-Benichou C, Gilbert T 1998 Regulation of c-ret expression by retinoic acid in rat metanephros: implication in nephron mass control. Am J Physiol 275:F938-F945

36. Vilar J, Gilbert T, Moreau E, Merlet-Benichou C 1996 Metanephros organogenesis is highly stimulated by vitamin A derivatives in organ culture. Kidney Int 49:14781487

37. Costantini F 2006 Renal branching morphogenesis: concepts, questions, and recent advances. Differentiation 74:402-421 